\title{
Assessment of Nutritional Status in the Critically Ill
}

\author{
Shiva K Narayan ${ }^{1}$, Kiran K Gudivada ${ }^{2}$, Bhuvana Krishna ${ }^{3}$ \\ Keywords: Critically ill adults, Intensive care, Malnutrition, Nutritional assessment, Nutritional status. \\ Indian Journal of Critical Care Medicine (2020): 10.5005/jp-journals-10071-23617
}

\section{INTRODUCTION}

In critically ill patients, the prevalence of malnutrition ranges between $38 \%$ and $78 \%$. At admission to hospital, at least one-third of patients have some degree of malnutrition and two-thirds of them progress to further decline without adequate nutritional provision. Additionally, two-thirds of patients who were without malnutrition will become malnourished during hospitalization. ${ }^{1-3}$ Many studies have shown that malnutrition is an independent risk factor for nosocomial infections and higher readmissions rates. Early identification and appropriate nutritional intervention in malnourished patients has consistently shown to decrease hospital stay, infectious complications, and overall cost. ${ }^{4}$ Nutritional assessment in critically ill patients is challenging, best method to identify patients susceptible to malnutrition has not yet been identified. Various risk factors and nutritional risk scores have been proposed. In this review article, we will be discussing briefly on the pathophysiology of malnutrition, the importance of nutritional risk screening (NRS 2002) and assessment, and finally the practical implications of bedside nutritional assessment.

\section{Malnutrition in Critically Ill: Pathophysiology}

Malnutrition is defined as any variation in degree of nutrition (either overnutrition or undernutrition) with or without inflammation that has led to variations in body composition. ${ }^{5}$ According to a consensus statement by the Academy of Nutrition and Dietetics (AND) and the American Society for Parenteral and Enteral Nutrition (A.S.P.E.N.) malnutrition is defined as the presence of any two or more of these entities: Insufficient energy, intake, weight loss, loss of muscle mass, loss of subcutaneous fat, localized or generalized fluid accumulation, or decreased functional status. ${ }^{6}$ Critical illness is a life-threatening condition characterized by infection, trauma, or any medical illness. It involves massive surge of proinflammatory mediators, which incites host catabolism. Proinflammatory response to infection or trauma is body's adaptive mechanism to defend against pathogens and to supplement substrates for healing. However, severe proinflammatory response is counterproductive; hence, body mounts an anti-inflammatory response to counterbalance the damage. On occasions when the balance shifts toward excess anti-inflammatory state, the immune paralysis thus created may not be effective enough to eradicate the pathogens. ${ }^{7}$ Therefore, a delicate balance should exist between pro- and anti-inflammatory states to facilitate appropriate host immune response. Nutrition plays a vital role in modulating host immune response, maintaining muscle mass, slowing catabolism, and maintaining gastrointestinal mucosal integrity and immunity (Flowchart 1). ${ }^{8}$

\author{
${ }^{1-3}$ Department of Critical Care Medicine, St. John's Medical College, \\ Bengaluru, Karnataka, India \\ Corresponding Author: Bhuvana Krishna, Department of Critical \\ Care Medicine, St. Johns Medical College, Bengaluru, Karnataka, India, \\ Phone: +91 9945693221, e-mail: bhuvana.11@gmail.com
}

How to cite this article: Narayan SK, Gudivada KK, Krishna B. Assessment of Nutritional Status in the Critically III. Indian J Crit Care Med 2020;24(Suppl 4):S152-S156.

Source of support: Nil

Conflict of interest: None

For better understanding, the pathophysiology of malnutrition can be discussed in two entities: Stress catabolism and inadequate nutrition intake. In critical illness, catabolic hormones and proinflammatory mediators are released to enhance catabolism. Catabolic hormones, such as, glucagon, cortisol, and catecholamines, are secreted and nutrition reserves will be mobilized. There will be generation of endogenous substrates like glucose, amino acids, and free fatty acids. These substrates will be delivered to sustain function of the vital organs. ${ }^{9}$ Proinflammatory mediators like IL-1, IL-6, and TNF-alpha that are produced as a result of infection or injury will further exaggerate catabolism. ${ }^{9}$ During such states, the priority is to provide adequate nutrition support to optimize function of vital organs and to promote appropriate host immune response. ${ }^{10}$ In addition, most critically ill patients have a lower nutritional reserve, compounding to the restricted food intake during intensive care unit (ICU) and hospital stay, prolonged fasting and frequent interruptions in feeding further promote iatrogenic underfeeding and worsening malnutrition. ${ }^{11}$ Early identification and prompt initiation of feeding can hasten the recovery from critical illness. Few early indicators of malnutrition are mentioned in the Table 1.

There are two steps needed for the diagnosis of malnutrition. The first step requires a validated screening tool to identify patients at risk of malnutrition and the second step involves its diagnosis and grading the severity of malnutrition. ${ }^{13}$

\section{Nutritional Risk Screening}

Nutritional screening is performed to critically ill patients to identify the patients at high risk of malnutrition. American Society for Parenteral and Enteral Nutrition has defined nutritional screening as "A process to identify an individual who is malnourished or who is at risk for malnutrition to determine if a detailed nutrition assessment is indicated". ${ }^{14}$ Screening is best done within 24 to 48 hours of hospital admission by the treating doctors. Screening can

() The Author(s). 2020 Open Access This article is distributed under the terms of the Creative Commons Attribution 4.0 International License (https://creativecommons. org/licenses/by-nc/4.0/), which permits unrestricted use, distribution, and non-commercial reproduction in any medium, provided you give appropriate credit to the original author(s) and the source, provide a link to the Creative Commons license, and indicate if changes were made. The Creative Commons Public Domain Dedication waiver (http://creativecommons.org/publicdomain/zero/1.0/) applies to the data made available in this article, unless otherwise stated. 
Flowchart 1: Pathophysiology of malnutrition in critically illness: Various pathways leading to malnutrition in critical illness. Crucial points where nutritional interventions help to improve the outcomes

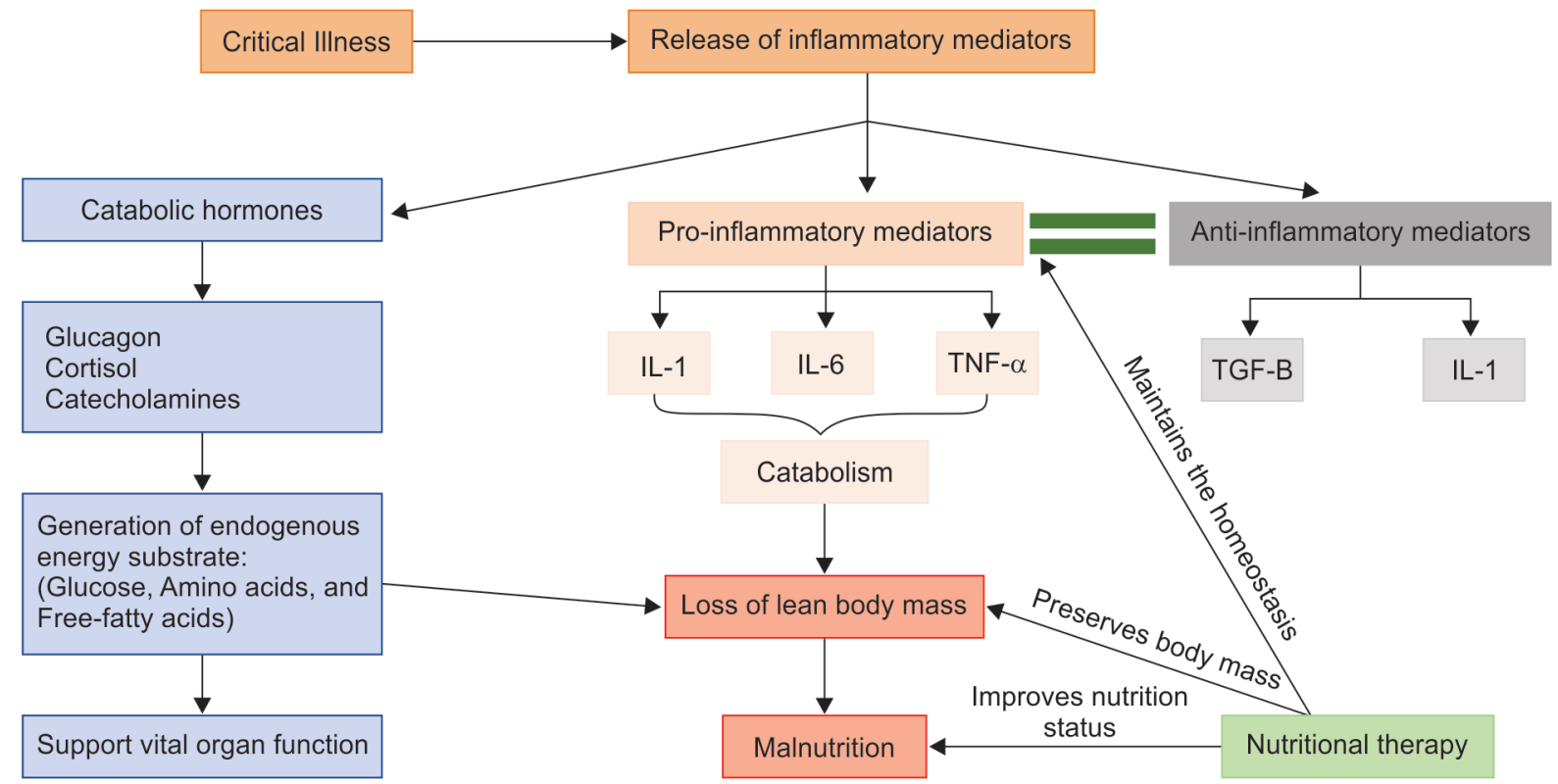

also provide a timeline of patient's nutritional status during the course of hospital stay.

\section{Nutritional Screening Tools and Methods}

An ideal screening tool should have adequate validity, reliability, sensitivity, specificity, and positive predictive value for detecting high-risk patients. However, no screening tool till date has been able to fulfill these criteria. There are many nutritional screening assessment tools that have been studied. Most have incorporated inflammatory system biomarkers and severity scores as these two are closely related to the pathophysiology of malnutrition in critically ill patients. ${ }^{15}$ The screening tools must assess dietary, physical, anthropometric, psychological, social, and clinical factors. Each variable assessed must be justified with an evidence-based risk factor or outcome. The tools must also be simple to use at the bedside and cost-effective. The screening tools are mostly a questionnaire and a final score is derived. These scores are further validated by prospective studies in critically ill population. ${ }^{13}$

Among all the screening tools, only the NRS 2002 and the Nutrition Risk in the Critically ill (NUTRIC) have been extensively studied. $^{15}$

\section{Nutritional Risk Screening 2002}

The nutritional risk screening 2002 (NRS 2002) was developed by Kondrup et al. ${ }^{16}$ The Dutch group developed the tool which included recent dietary intake, disease severity, and weight loss. A NRS score of $\geq 3$ indicated severe risk of malnutrition and NRS score of 0 indicated absence of malnutrition. The screening tool was validated in many previously published randomized control trials. A high NRS 2002 score was able to predict poor outcome in non-critically ill patients but not in critically ill patients. ${ }^{15}$ The assessment of weight loss and dietary intake may be difficult in critical care settings. One of the main limitations of the NRS 2002 score is that any critically ill patient with APACHE II score above 10 will fall in the high-risk category (Tables 2 to 4 ).
Table 1: Patients at risk of malnutrition ${ }^{12}$

- Being grossly underweight ( $<80 \%$ ideal body weight).

- Being grossly overweight (>120\% ideal body weight).

- Recent weight loss (>10\% over 3 months).

- Being alcoholic/substance dependent.

- Nil permouth for $>5$ days.

- Increased nutrient losses.

- Malabsorption.

- Short bowel syndrome.

- Fistulae.

- Draining abscesses or wounds/burns.

- Renal dialysis.

- Increased nutrient requirements.

- Trauma.

- Burns.

- Sepsis.

- Taking medication with anti-nutrient properties.

\section{Nutrition Risk in the Critically III}

Heyland et al. ${ }^{18}$ developed a screening tool for critically ill patients. Previous screening tools implicated all critically ill patients in high-risk category and no screening tool was studied exclusively in critically ill population. Heyland et al. ${ }^{18}$ in a prospective observational multicenter study, data were collected, and a multivariable model was developed. The authors selected the parameters based on a conceptual model of malnutrition in critically ill including inflammatory markers, severity illness scores, and developed the scoring system. The NUTRIC score was able to discriminate critically ill patients who will benefit from aggressive protein energy provision. This was the first screening tool that was validated and developed in critically ill patients. The score can be easily calculated with parameters measured in daily care of critically 
Table 2: Nutritional risk screening and assessment tools that have been studied ${ }^{14}$

\begin{tabular}{|c|c|c|}
\hline Instrument & Anthropometry and/or diet related & Severity of illness \\
\hline Birmingham nutrition risk score & Weight loss, BMI, appetite, ability to eat & Stress factor (severity of diagnosis) \\
\hline Malnutrition screening tool & Appetite, unintentional weight loss & \\
\hline Malnutrition universal screening tool & BMI, change in weight & Presence of acute disease \\
\hline Maastricht index & Percentage ideal body weight & Albumin, prealbumin, lymphocyte count \\
\hline Nutrition risk classification & $\begin{array}{l}\text { Weight loss, percentage ideal body weight, } \\
\text { dietary intake }\end{array}$ & \\
\hline Nutritional risk index & Present and usual body weight & Albumin \\
\hline Nutritional risk screening 2002 & Weight loss, BMI, food intake & Diagnosis (severity) \\
\hline $\begin{array}{l}\text { Prognostic inflammatory and nutritional } \\
\text { index }\end{array}$ & & $\begin{array}{l}\text { Albumin, prealbumin, C-reactive protein, a1- } \\
\text { acid glycoprotein }\end{array}$ \\
\hline Prognostic nutritional index & Triceps skinfold & Albumin, transferrin, skin sensitivity \\
\hline Simple screening tool & BMI, percentage weight loss & Albumin \\
\hline Short nutrition assessment questionnaire & $\begin{array}{l}\text { Recent weight history, appetite, use of oral } \\
\text { supplement or tube feeding }\end{array}$ & \\
\hline NUTRIC (nutrition risk in the critically ill) & Nil & APACHE II \\
\hline Mini nutritional assessment & $\begin{array}{l}\text { Weight, height, mid-arm and circumference, } \\
\text { diet history, appetite, feeding mode }\end{array}$ & $\begin{array}{l}\text { Albumin, prealbumin, cholesterol, } \\
\text { lymphocyte count }\end{array}$ \\
\hline Subjective global assessment (SGA) & Weight and diet history & Primary diagnosis, stress level \\
\hline
\end{tabular}

Table 3: Nutritional risk screening $2002^{16,17}$

\begin{tabular}{|c|c|c|c|}
\hline Nutritional status & Score & Stress metabolism (severity of disease) & Score \\
\hline None & 0 & None & 0 \\
\hline Moderate & 2 & Moderate stress metabolism & 2 \\
\hline Weight loss $>5 \%$ in 2 months & & Patient is bedridden due to illness & \\
\hline BMI $18.5-20.5 \mathrm{~kg} / \mathrm{m}^{2}$ AND & & Highly increased protein requirement & \\
\hline Reduced general condition & & Stroke, hematologic cancer, severe pneumonia, extended abdominal surgery & \\
\hline \multicolumn{4}{|l|}{ OR } \\
\hline \multicolumn{4}{|c|}{$\begin{array}{l}25-50 \% \text { of the normal food intake in } \\
\text { the last week }\end{array}$} \\
\hline Severe & 3 & Severe stress metabolism & 3 \\
\hline Weight loss $>5 \%$ in 1 month & & Patient is critically ill (intensive care unit) & \\
\hline OR & & $\begin{array}{l}\text { Very strongly increased protein requirement can only be achieved with parenteral } \\
\text { nutrition }\end{array}$ & \\
\hline $\begin{array}{l}\mathrm{BMI}<18.5 \mathrm{~kg} / \mathrm{m}^{2} \mathrm{AND} \text { reduced } \\
\text { general condition }\end{array}$ & & APACHE II > 10, bone marrow transplantation, head traumas & \\
\hline \multicolumn{4}{|l|}{ OR } \\
\hline $\begin{array}{l}0-25 \% \text { of the normal food intak } \\
\text { the last week }\end{array}$ & & & \\
\hline
\end{tabular}

ill patients. Addition of IL-6 marker was called as modified NUTRIC score by the authors. However, the addition of IL- 6 did not improve the discriminative ability of the score; hence, the authors suggest using the score also when IL- 6 values are not available. ${ }^{18}$

The A.S.P.E.N./society of critical care medicine guidelines suggest using either NRS 2002 or NUTRIC/m NUTRIC for nutritional screening in critically ill patients. ${ }^{19}$ The NUTRIC score is more useful in critically ill patients as it was developed in critically ill patients and recent food intake and weight change which is difficult to obtain in ICU patients were not included. The limitations of the NUTRIC score were that it did not include nutritional parameters and also micronutrient deficiencies were not included. The NUTRIC score is still not prospectively tested in a randomized control trial. The NUTRIC score performed better as compared to the MUST score in critically ill patients. ${ }^{20}$ Comparative studies between NUTRIC and NRS 2002 scores showed inconsistent results. In one retrospective study, NRS 2002 showed higher sensitivity and specificity for the diagnosis of malnutrition when compared to NUTRIC score, ${ }^{21}$ while another retrospective study by Canales et al. $^{22}$ found that NUTRIC score was superior to NRS 2002 for assessing malnutrition risk. An observational study by Coltman et al. ${ }^{23}$ found that NUTRIC score was no different to routine screening. In a recent observational study, NUTRIC score was also able identify high-risk critically ill COVID-19 patients. ${ }^{24}$ 


\begin{tabular}{lll} 
Table 4: NUTRIC score variables $^{18}$ & & \\
\hline Variable & Range & Points \\
\hline Age & $<50$ & 0 \\
& 50 to $<75$ & 1 \\
& $>75$ & 2 \\
APACHE II & $<15$ & 0 \\
& 15 to $<20$ & 1 \\
& $20-28$ & 2 \\
& $>28$ & 3 \\
SOFA & $<6$ & 0 \\
& 6 to $<10$ & 1 \\
& $>10$ & 2 \\
Number of comorbidities & $0-1$ & 0 \\
Days from hospital to ICU admission & $>2$ & 1 \\
& 0 to $<1$ & 0 \\
IL-6 & $>1$ & 1 \\
& 0 to $<400$ & 0 \\
\end{tabular}

Table 5: NUTRIC scoring system: if IL-6 available

\begin{tabular}{|c|c|c|}
\hline Sum of points & Category & Explanation \\
\hline $6-10$ & High score & $\begin{array}{l}\text { - Associated with worse clinical } \\
\text { outcomes (mortality, ventilation). } \\
\text { - These patients are the most } \\
\text { likely to benefit from aggressive } \\
\text { nutrition therapy. }\end{array}$ \\
\hline $0-5$ & Low score & $\begin{array}{l}\text { These patients have a low } \\
\text { malnutrition risk. }\end{array}$ \\
\hline
\end{tabular}

\section{Nutritional Assessment}

Nutritional assessment is a formal assessment of the nutritional status of a patient by a trained healthcare professional usually a dietician, and results in nutrition-related diagnosis. ${ }^{15}$ Once a patient is identified as at risk from the screening tools detailed, nutritional assessment should be performed. Indian Society of Critical Care Medicine practice guidelines for nutrition in critically ill patients recommend the nutritional assessment by Subjective Global Assessment (SGA). ${ }^{25}$ Assessment by anthropometry like body mass index (BMI) is difficult to measure in critical care setting. Measurement of serum albumin, transferrin, and prealbumin is not reliable in critically ill patients (Tables 5 and 6).

\section{Subjective Global Assessment}

It is a subjective nutritional assessment tool initially developed for post-gastrointestinal surgery patients. ${ }^{26}$ The tool was later studied in critically ill patients. The SGA scale includes parameters to assess subcutaneous fat, muscle wasting, fluid retention, weight change, recent food intake, gastrointestinal symptoms, and functional capacity. Subjective Global Assessment class $C$ includes severe malnutrition, SGA class $B$ includes moderate malnutrition, and SGA class $A$ includes no malnutrition. In a meta-analysis of studies of use of SGA in critically ill patients, SGA was more favorable than other assessment tools and SGA grade B and C had poor outcomes. ${ }^{3}$ Subjective Global Assessment is simple and easy to assess at the bedside and is cost-effective also. The main limitations of SGA were that severity of illness were not included, assessment of weight and
Table 6: NUTRIC scoring system: If no IL-6 available*

\begin{tabular}{|c|c|c|}
\hline Sum of points & Category & Explanation \\
\hline $5-9$ & High score & $\begin{array}{l}\text { - Associated with worse } \\
\text { clinical outcomes (mortality, } \\
\text { ventilation). } \\
\text { - These patients are the most } \\
\text { likely to benefit from aggressive } \\
\text { nutrition therapy. }\end{array}$ \\
\hline $0-4$ & Low score & $\begin{array}{l}\text { These patients have a low } \\
\text { malnutrition risk. }\end{array}$ \\
\hline
\end{tabular}

*It is acceptable to not include IL-6 data when it is not routinely available; it was shown to contribute very little to the overall prediction of the NUTRIC score

food history in critically ill patients was difficult, changes in SGA grade takes a long time usually many days.

Besides the subjective assessment, it is also important to assess the gastrointestinal tract with gastric residual volumes to assess the nutritional status in critically ill patients. ${ }^{15}$

Other methods studied were use of computed tomography (CT) scan to assess the muscle mass, as CT scan is cumbersome use of ultrasonography assessment of quadriceps muscle thickness has been studied. Ultrasonography is a simple, noninvasive, bedside tool to assess muscle mass. It can be performed serially and detect short-term changes. A prospective study by Rodrigues et al. ${ }^{27}$ assessed quadriceps and rectus femoris muscle thickness using ultrasonography and the reduction in muscle mass was correlated with severe malnutrition. Ultrasonographic assessment of muscle mass needs further validation and is a useful future tool. Bioelectrical impedance is another tool used to measure fat free mass; however, the fluid electrolyte imbalance in critically ill patients affects the measurements taken.

\section{Practical Implications of Nutritional Assessment in Critically Ill Patients}

Nutrition assessment and prescription in critically ill patients is often ignored world over. International guidelines recommend that every patient should be screened for malnutrition within 24-48 hours of ICU admission, as many of these patients are at a risk or may have malnutrition at admission to ICU due to the underlying severity of the illness.

Malnutrition and muscle wasting set in early during the ICU stay because of the imbalance between energy and protein requirements and intake. A trained nutrition expert or a dietician is not necessary to identify patients who are, or at risk of malnutrition. Nutrition assessment starts with a good patient history and physical examination for emaciation and loss of muscle mass. But loss of muscle function may occur much before loss of muscle mass, which may go unnoticed in an obese or fluid retained critically ill patient, unless actively screened. Anthropometric measurements like patient's weight in ICU is technically difficult and may fluctuate widely due to fluid shifts during the ICU stay.

The NUTRIC score is an easy screening tool which can be used at the bedside. If found at risk the patient should be assessed in detail by a nutritionist/dietician or by the treating clinician if nutritionist is not available. Nutritional assessment should be performed using the SGA tool. The SGA although validated in critically ill 
patients has its limitations; to obtain the necessary anthropometric measurements and muscle function assessment in a sedated patient may be near impossible.

Body composition assessment using ultrasound, computed tomography, and bioimpedance are relatively new tools and technically limited in critically ill patients, currently being used only for research.

Nutrition screening and assessment should be a continuous process for all hospitalized patients so as to intervene early with necessary protein and energy supplementation.

\section{CONCLUSION}

Patients in ICU are at a high risk of malnutrition and poor outcomes related to it. Assessment of nutritional status is not an easy process. There is no gold standard assessment score or tool available for nutritional assessment. However, it is important to assess the critically ill patients using the best tools available and institute optimal nutrition to these patients. Further research is warranted for a better validated screening tool for nutrition assessment in the critically ill.

\section{References}

1. Bistrian BR, Blackburn GL, Vitale J, Cochran D, Naylor J. Prevalence of malnutrition in general medical patients. JAMA 1976;235(15):15671570. DOI: 10.1001/jama.1976.03260410023017.

2. Braunschweig C, Gomez S, Sheean PM. Impact of declines in nutritional status on outcomes in adult patients hospitalized for more than 7 days. J Am Diet Assoc 2000;100(11):1316-1322. DOI: 10.1016/ S0002-8223(00)00373-4.

3. Lew CCH, Yandell R, Fraser RJ, Chua AP, Chong MFF, Miller M. Association between malnutrition and clinical outcomes in the intensive care unit: a systematic review. J Parenter Enter Nutr 2017;41(5):744-758. DOI: 10.1177/0148607115625638.

4. Jolliet P, Pichard C, Biolo G, Chioléro R, Grimble G, Leverve $X$, et al. Enteral nutrition in intensive care patients: a practical approach. Clin Nutr 1999;18(1):47-56. DOI: 10.1054/clnu.1998.0001.

5. Soeters PB, Schols AM. Advances in understanding and assessing malnutrition. Curr Opin Clin Nutr Metab Care 2009;12(5):487-494. DOI: 10.1097/MCO.0b013e32832da243.

6. White JV, Guenter P, Jensen G, Malone A, Schofield M, Group AMW, et al. Consensus statement of the Academy of Nutrition and Dietetics/ American Society for Parenteral and Enteral Nutrition: characteristics recommended for the identification and documentation of adult malnutrition (undernutrition). J Acad Nutr Diet 2012;112(5):730-738. DOI: $10.1177 / 0148607112440285$.

7. Zhang JM, An J. Cytokines, Inflammation and pain. Int Anesthesiol Clin 2007:45(2):27-37. DOI: 10.1097/AIA.0b013e318034194e.

8. Demling RH. Nutrition, anabolism, and the wound healing process: an overview. Eplasty 2009;9:e9.

9. Preiser J-C, Ichai C, Orban J-C, Groeneveld ABJ. Metabolic response to the stress of critical illness. Br J Anaesth 2014;113(6):945-954. DOI: 10.1093/bja/aeu187.

10. Kondrup J. Nutritional-risk scoring systems in the intensive care unit. Curr Opin Clin Nutr Metab Care 2014;17(2):177-182. DOI: 10.1097/ MCO.0000000000000041.

11. Lee Z-Y, Ibrahim NA, Mohd, Yusof BN. Prevalence and duration of reasons for enteral nutrition feeding interruption in a tertiary intensive care unit. Nutrition 2018;53:26-33. DOI: 10.1016/j. nut.2017.11.014.

12. Prins. Nutritional assessment of the critically ill patient. South Afr J Clin Nutrit 2010;23(1):11-18. DOI: 10.1080/16070658.2010.11734253.

13. Rajendram $R$, Khan MF. The use of nutritional screening tools in the intensive therapy unit. Anaesth Pain Intens Care 2019;23(2):231-236. DOI: 10.35975/apic.v23i2.1081.

14. Mueller C, Compher C, Ellen DMASPEN. Clinical guidelines: Nutrition screening, assessment, and intervention in adults. JPEN J Parenter Enteral Nutr 2011;35(1):16-24. DOI: 10.1177/ 0148607110389335.

15. Lee, Z-Y, Heyland DK. Determination of nutrition risk and status in critically ill patients: what are our considerations? Nutr Clin Pract 2019;34(1):96-111. DOI: 10.1002/ncp.10214.

16. Kondrup J, Rasmussen HH, Hamberg O, Stanga Z, Ad Hoc ESPEN Working Group. Nutritional risk screening (NRS 2002): a new method based on an analysis of controlled clinical trials. Clin Nutr 2003;22(3):321-336. DOI: 10.1016/s0261-5614(02)00214-5.

17. Reber E, Gomes F, Vasiloglou MF, Schuetz P, Stanga Z. Nutritional risk screening and assessment. J Clin Med 2019;8(7):1065. DOI: 10.3390/ jcm8071065.

18. Heyland DK, Dhaliwal R, Jiang X, Day AG. Identifying critically ill patients who benefit the most from nutrition therapy: the development and initial validation of a novel risk assessment tool. Crit Care 2011;15(6):R268. DOI: 10.1186/cc10546.

19. McClave SA, Taylor BE, Martindale RG, Warren MM, Johnson DR, Braunschweig $C$, et al. Guidelines for the provision and assessment of nutrition support therapy in the adult critically ill patient: Society of critical care medicine (SCCM) and American society for parenteral and enteral nutrition (A.S.P.E.N.). J Parenter Enteral Nutr. 2016;40(2):159-211. DOI: 10.1177/0148607115621863.

20. de Vries MC, Koekkoek WK, Opdam MH, van Blokland D, van Zanten AR. Nutritional assessment of critically ill patients: validation of the modified NUTRIC score. Eur J Clin Nutr 2018;72(3):428-435. DOI: 10.1038/s41430-017-0008-7.

21. Rattanachaiwong S, Zribi B, Kagan I, Theilla M, Heching M, Singer P. Comparison of nutritional screening and diagnostic tools in diagnosis of severe malnutrition in critically ill patients. Clin Nutr 2020;20(Suppl):S0261-S5614. DOI: 10.1016/j.clnu.2020.02.035.

22. Canales C, Elsayes A, Yeh DD, Belcher D, Nakayama A, McCarthy CM. Nutrition risk in critically ill versus the nutritional risk screening 2002: are they comparable for assessing risk of malnutrition in critically ill patients? J Parent Enteral Nutrit 2019;43(1):81-87. DOI: 10.1002/ jpen.1181.

23. Coltman A, Peterson S, Roehl K, Roosevelt H, Sowa D. Use of 3 tools to assess nutrition risk in the intensive care unit. J Parent Enteral Nutrit 2015;39(1):28-33. DOI: 10.1177/0148607114532135.

24. Zhang $P, H e ~ Z, Y u$ G, Peng D, Feng $Y$, Ling J, et al. The modified NUTRIC score can be used for nutritional risk assessment as well as prognosis prediction in critically ill COVID-19 patients. Clin Nutr 2020;20(Suppl):30288-0. DOI: 10.1016/j.clnu.2020.05.051.

25. Mehta Y, Sunavala JD, Zirpe K, Tyagi N, Garg S, Sinha S, et al. Practice guidelines for nutrition in critically ill patients: a relook for Indian scenario. Indian J Crit Care Med 2018;22(4):263-273. DOI: 10.4103/ ijccm.IJCCM_3_18.

26. Detsky A, McLaughlin JR, Baker J, Johnston N, Whittaker S, Mendelson RA, et al. What is subjective global assessment of nutritional status? J Parenter Enteral Nutr 1987;11(1):8-13. DOI: 10.1177/014860718701100108.

27. Rodrigues CN, Ribeiro Henrique J, Ferreira ÁRS, Correia MITD. Ultrasonography and other nutrition assessment methods to monitor the nutrition status of critically ill patients. J Parent Enteral Nutrit 2020;10:1002. DOI: 10.1002/jpen.1966. 